\title{
Urban Analysis and Space Syntax Theory: study and mapping of the city of Juiz de Fora, Brazil
}

\section{SIGRADI2018 TECHNOPOLITICAS \\ xxii congresso da sociedade iberoamericana de gráfica digital 22th conference of the iberoamerican society of digital graphics $07|08| 09 \mid$ novembro|2018 iau usp | são carlos $\mid \mathrm{sp}$ br}

\author{
Julia Paglis \\ Federal University of Juiz de Fora | Brazil | julia.paglis@arquitetura.ufjf.br \\ Guilherme Brandão \\ Federal University of Juiz de Fora | Brazil | guilherme.loures@engenharia.ufj.br \\ Fernando Lima \\ Federal University of Juiz de Fora | Brazil | fernando.lima@ufjf.edu.br \\ Francisco Serdoura \\ University of Lisbon | Portugal | fs@fa.ulisboa.pt
}

\begin{abstract}
This paper is a result of a research that uses the Space Syntax Theory for analysis of the city of Juiz de Fora, Brazil. After elaborating the axial map, based on data collection available by the City Hall, some analysis of the city were made using the syntactic measures: Integration $\mathrm{HH}$, Mean Depth and Total Depth. The focus of the analysis was on the central area of the city, called "Central Triangle". As a result, the analyzes make it possible to identify that the initial urban center remains as the point of convergence of several urban areas of the city, consolidating itself as an area with great potential.
\end{abstract}

Keywords: Space Syntax; Urban analysis; Central area; Juiz de Fora.

\section{INTRODUÇÃO}

O presente trabalho é resultado de uma pesquisa colaborativa entre o laboratório de pesquisa (omitido para revisão) e o laboratório (omitido para revisão). Esta pesquisa, iniciada em 2017 e intitulada de: (omitido para revisão), procura verificar as possibilidades de utilização da Teoria da Sintaxe Espacial para descrever e analisar aspectos relativos à configuração urbana da cidade de Juiz de Fora, no estado de Minas Gerais, Brasil. Cabe ressaltar ainda que, até o início da investigação em questão, não foram encontrados registros de que a cidade havia sido analisada de maneira plena por meio da Sintaxe Espacial, tampouco que havia sido descrita (considerando toda sua extensão) por meio de um mapa axial.

A cidade de Juiz de Fora apresenta certas características, que conferem à utilização da Sintaxe Espacial contornos interessantes para avaliação. A topografia e algumas especificidades da malha da cidade sugerem que os resultados obtidos por meio das medidas sintáticas sejam analisados com cautela. De acordo com 0 arquivo planialtimétrico cedido pela prefeitura de Juiz de Fora, a região central do município encontra desníveis com mais de 200 metros, o que muda completamente a maneira com que se deve ler e entender os valores das medidas sintáticas.

\section{BREVE HISTÓRICO DA CIDADE}

Juiz de Fora é uma cidade do sudeste mineiro que tem seu histórico de desenvolvimento diretamente ligado ao ciclo cafeeiro e à implantação da ferrovia no início da década de 1870, então Estrada de Ferro D. Pedro II, para escoamento da produção. A queda da produção aurífera em Minas Gerais, seguida da valorização internacional da produção cafeeira, na qual a cidade de Juiz de Fora chegou a ser a segunda maior produtora do estado e, por fim, a chegada da Estrada de Ferro D. Pedro II, propiciaram o acúmulo de capital e as condições para o desenvolvimento da cidade (Sampaio, 2015).

Em pouco mais de meio século, entre os anos de 1810 e 1880, a cidade passa de um espaço quase vazio, predominantemente ocupado ao longo do caminho novo da Estrada Real por fazendas e paragens, na margem esquerda do Rio Paraibuna, para uma cidade referência na então província de Minas Gerais. Seu núcleo urbano inicial desenvolveu-se à margem direita do Rio Paraibuna, entre a Estrada do Paraibuna e a Estrada União e Indústria, construída por Mariano Procópio Ferreira Lage para ligar a cidade à capital do império, passando por Petrópolis, esboçando-se as linhas básicas de desenvolvimento da cidade que permanecem até os dias atuais (Miranda, 1990). 


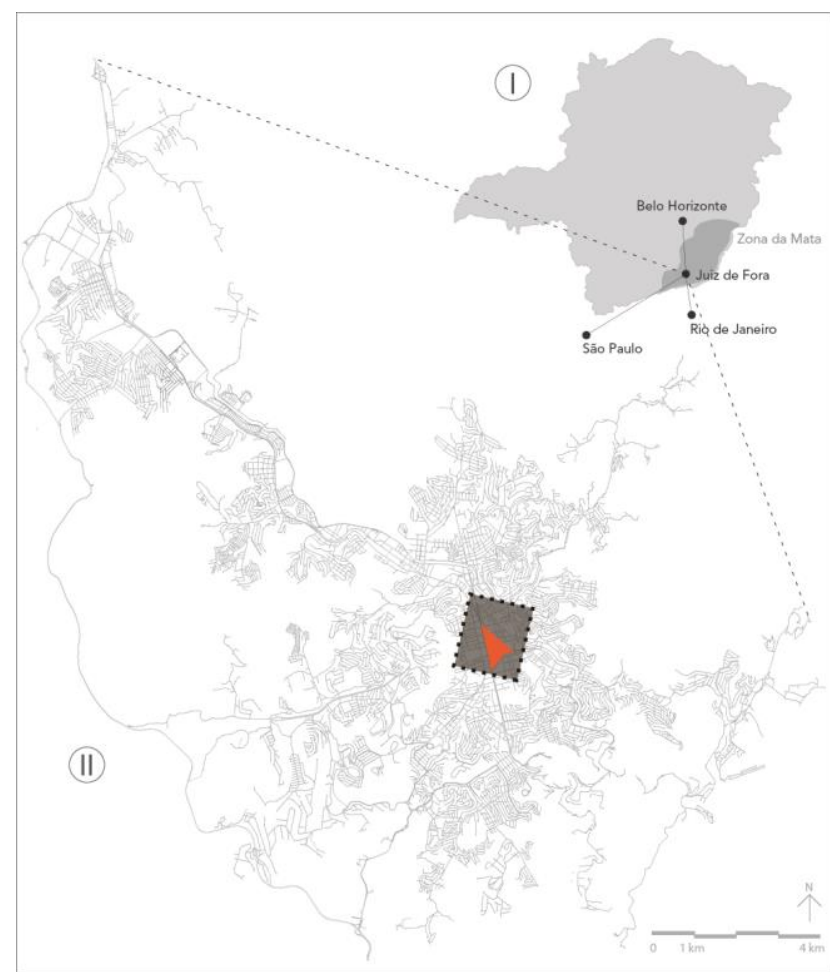

Figura 1: Localização da cidade de Juiz de Fora no estado de Minas Gerais (I) com destaque para a inserção do triângulo central na malha urbana (II). Fonte: autores.

A longa Estrada do Paraibuna, atual Avenida Barão do Rio Branco, cortava a cidade no sentido norte-sul; interceptada pela Estrada União e Indústria, atual Avenida Getúlio Vargas e, por fim, limitada pela Rua da Califórnia, atual Rua Halfeld, configurando o triângulo central que, posteriormente, seria expandido (Figura 1). Com o passar do tempo, novas linhas de evolução da cidade foram se estabelecendo - direcionadas principalmente pelos eixos da ferrovia e do rio Paraibuna (Lessa, 1985).

Abdalla, 1996 e Braida, 2008, apontam que, do ponto de vista morfológico, a configuração do triângulo central de Juiz de Fora pode ser compreendida por três elementos formadores: a) o traçado ortogonal originado pelos Planos Urbanos de Halfeld e Dodt (1860), que se apropriam da Estrada do Paraibuna como eixo estruturador; b) a implantação dos empreendimentos da Estrada União e Indústria, da estrada de Ferro D. Pedro II e das correções de curso do Rio Paraibuna, que conformaram grandes áreas passíveis de ocupação, e; c) o traçado das galerias comerciais da cidade, possibilitando aos pedestres a transposição dos grandes quarteirões centrais.

A Avenida Barão do Rio Branco firmou-se como o principal eixo estruturador da malha urbana e seu cruzamento com a Rua Halfeld, marcado pela ortogonalidade propiciada pela localização do centro de Juiz de Fora na área plana do vale do Paraibuna, é considerado o ponto central de Juiz de Fora (Abdalla, 1996; Braida, 2008).

Com o tempo, o núcleo urbano inicial expandiu-se ao longo do Eixo do Paraibuna e da estrada de ferro, consolidando a malha urbana e a ligação entre áreas até então espacialmente separadas, conformando o atual tecido urbano da cidade, alongado no sentido norte-sul, quase completamente conectado, como mostra figura 1 (Lessa, 1985).

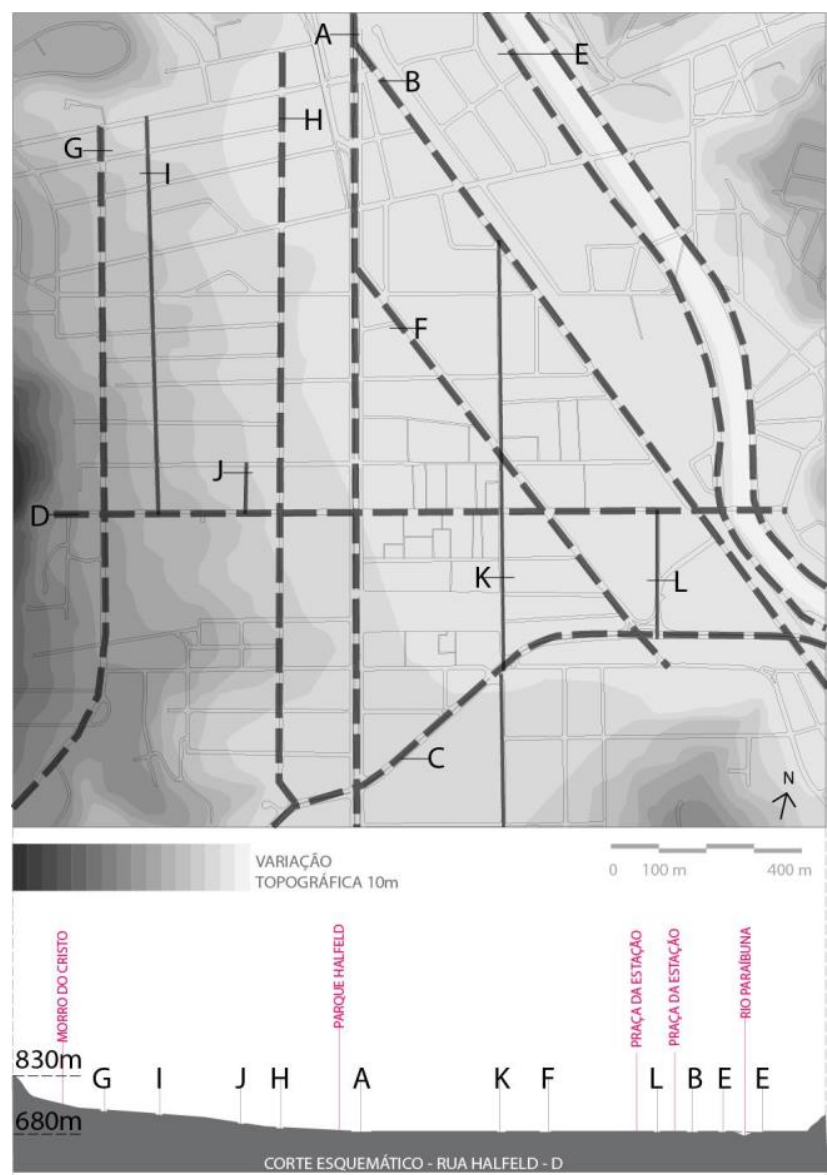

LEGENDA

\begin{tabular}{ll|cl} 
A & AV. RIO BRANCO & G & RUA OLÉGARIO MACIEL \\
B & AV. FRANCISCO BERNARDINO & H & RUA SANTO ANTONIO \\
C & AV. ITAMAR FRANCO & I & RUA TIRADENTES \\
D & RUA HALFELD & J & RUA GILBERTO DE ALENCAR \\
E & AV. BRASIL & K & RUA BATISTA DE OLIVEIRA \\
F & AV. GETÚLIO VARGAS & L & RUA DR. PAULO FRONTIN
\end{tabular}

Figura 2: Triângulo central de Juiz de Fora e altimetria esquemática longitudinal da rua Halfeld. Fonte: autores.

\section{SINTAXE ESPACIAL}

Para verificar as implicações e relações globais da forma urbana de Juiz de Fora, foi aplicada a Teoria da Sintaxe Espacial (SE), desenvolvida por Bill Hillier e Julienne Hanson (1984), e que sugere que a configuração urbana afeta o padrão de movimentação das pessoas pelas cidades, fazendo com que seja possível prever, com razoável nível de confiança, quais rotas serão mais comumente usadas e quais serão preteridas em razão dessa configuração.

A SE representa áreas urbanas de forma computacional (i. e. mapas axiais), fornecendo uma interface gráfica compreensível do espaço e facilitando o estudo das interrelações inerentes, possibilitando a análise de sistemas e estruturas complexas como as cidades e oferecendo ferramentas para a análise configuracional do sistema de vias e espaços urbanos capazes de quantificar inúmeras características do sistema (Medeiros, 2006). 
Geralmente, a estrutura espacial das cidades é entendida como configuração urbana, o que envolve a totalidade de relações entre os padrões de barreiras e permeabilidade que compõe a estrutura física do espaço. Isto significa que a estrutura física da cidade pode se apresentar mais ou menos favorável para que as pessoas realizem suas atividades em espaços específicos, incluindo a circulação de pedestres e veículos. Essa dicotomia entre barreira e permeabilidade é composta tanto por obstáculos ao movimento - como edifícios, grades, vegetação - quanto pelo sistema de espaços abertos que podem ser transpostos - vias, parques, praças, largos (Holanda, 2008).

A Sintaxe Espacial oferece instrumentos para entender e representar o espaço urbano em suas mais variadas escalas e funcionalidade, subsidiando a compreensão das relações entre as partes da cidade (quarteirões, espaços abertos, vias, etc.), em todo o sistema ou em recortes dele (Holanda, 2008). A partir da aplicação da teoria, torna-se claramente perceptível a definição de áreas com predominância de eixos de alto potencial de integração em oposição àquelas periféricas, menos integradas e com menor fluxo. Essa investigação permite medir, quantificar e distinguir diferentes níveis de conectividade entre cada rua específica em relação ao sistema na qual está inserido, estabelecendo então correlações, conexões e hierarquia entre as vias do complexo urbano (Medeiros, 2006).

O sistema de espaços abertos pode ser decomposto analiticamente em espaços axiais e espaços convexos, que afetam a forma com que as pessoas percebem 0 espaço à sua volta, fator essencial para a movimentação (Hillier et al, 1993). Os estudos que utilizam a SE para analisar as relações entre configuração urbana e mobilidade geralmente focam suas análises em mapas axiais, que são uma representação simplificada da malha urbana e suas ligações, figurando as barreiras e permeabilidade resultantes.

O mapa axial é obtido a partir do processamento digital das linhas resultantes de um desenho sobreposto à malha viária registrada pela base cartográfica da cidade, utilizando-se o menor número possível de linhas que representem o acesso direto através do espaço urbano. Após o processamento digital por programas computacionais específicos, mais comumente 0 Depthmap $\AA$, é possível gerar uma matriz de intersecções a partir da qual se calculam valores que correspondem às relações inter-axiais e que representam o potencial de atração de fluxos e movimentos de certo eixo urbano (Pereira et al, 2011). Estes potenciais podem ser indicados por valores numéricos ou representados através de uma gradação cromática que vai de vermelho para os de maior valor a azul para os de menor valor no critério analisado.

Vale ressaltar que, como exposto por Netto (2013), a SS não configura uma teoria da cidade - o que demandaria a capacidade de explicar no que esta consiste e as formas de transformação urbana - mas sim uma teoria que busca demonstrar e sistematizar as relações entre espaço e sociedade, mais precisamente no reconhecimento de uma relação objetiva entre a estrutura relacional e geométrica dos assentamentos humanos $e$ as restrições e potencialidades que elas impõem ao movimento e copresença, tratadas como um sistema de barreiras e permeabilidades.

Apesar de a SE não ser diretamente aplicada como ferramenta de estudo na cidade em si, os dados fornecidos pelos mapas, com diversos níveis de relações, possibilitam a decodificação do conhecimento de como as pessoas se deslocam mais provavelmente em relação às estruturas existentes, realizando prognósticos e prevendo fluxos (Gehl e Svarre, 2018).

\section{ELABORAÇÃo do MAPA dE SINTAXE ESPACIAL}

Utilizando a SE como aporte metodológico desta pesquisa, como primeira etapa de trabalho foi elaborado o mapa axial da cidade de Juiz de Fora, a partir do Levantamento Cadastral Municipal disponibilizado pela Prefeitura Municipal, elaborado em 2007, através de aerofotogrametria, tendo em vista as instruções presentes em Hillier e Hanson (1984). Para a elaboração do mapa axial, foi necessário estabelecer critérios iniciais, que podem ser alterados em futuras mudanças do mapa. Tais critérios foram:

a) vias existentes no levantamento cadastral, porém que não estavam ligadas de maneira direta ao sistema principal foram desconsideradas, sendo elas pavimentadas ou não pavimentadas

b) vias alternativas não-oficiais entre bairros, ou escadas que ligam vias não foram consideradas;

c) as vias utilizadas se baseiam nos limites definidos pelos quarteirões da cidade;

d) A Rodovia Federal BR-040 foi inserida ao mapa axial, por se tratar de um limite físico e antrópico;

e) devido a importância crucial para o funcionamento do comércio central da cidade, foram inseridas linhas axiais que se referem às principais galerias de pedestre que conectam quarteirões formados pelos limites das vias Avenidas Rio Branco, Av. Itamar Franco e Av. Francisco Bernardino, disponibilizadas digitalmente pelo Google Maps, uma vez que não constam no levantamento disponibilizado pela Prefeitura Municipal de Juiz de Fora;

f) para se descrever umas das Avenidas estruturantes da Cidade, Av. Rio Branco, optou-se por utilizar uma única linha axial, uma vez que não havia uma barreira visual e física de grande porte que impossibilitaria a passagem de pedestre. Vale-se ressaltar que esta avenida é formada por três seções viárias, que formam um sistema de mão único e binário, dividido uma pista central para o transporte público, e duas laterais para o transporte individual e coletivo particular.

A exposição desses critérios é fundamental, pois gerar um mapa axial característico para a cidade de Juiz de Fora, de maneira mais abrangente, sem excluir a possibilidade de um estudo mais aprofundado no futuro que leve em conta outros itens a serem considerados.

Ainda para a elaboração do mapa, teve-se que se lidar com o problema da topografia da cidade e da não 
retilinearidade da malha viária. Em certos pontos da cidade, o desnível pode ultrapassar de 200 metros, principalmente na área central que se localiza na parte mais baixa da cidade (fig. 02). Desta maneira optou-se, em um primeiro momento, por traçar as linhas axiais manualmente através da ferramenta computacional AutoCadR. Somente após a elaboração dessas que se utilizou o programa computacional Depthmap $\mathbb{R}$, para gerar o mapa axial da cidade de Juiz de Fora.

A seguir, o mapa topológico foi carregado no software DepthMap® X e convertido em mapa axial, possibilitando a utilização das seguintes medidas sintáticas: a) integração, que expressa o potencial de acessibilidade topológica calculado para o sistema como um todo; b) profundidade média, que expressa a distância linear entre o ponto central de cada segmento de via e os pontos centrais de todos os demais segmentos, para um número limitado de segmentos, e; c) profundidade total, que expressa a distância linear entre o ponto central de cada segmento de via e os pontos centrais de todos os outros segmentos (Hillier, 1996).

A escolha pela análise destas medidas sintáticas se deu pelo fato que:

a) a Integração $(\mathrm{HH})$ é utilizada normalmente para indicar a susceptibilidade da presença dos indivíduos em um determinado espaço, ligando-a diretamente às atividades de encontro social ou àquelas relacionadas ao comércio;

b) a profundidade média foi escolhida por determinar a quantidade média de passos topológicos entre um segmento e todos demais segmentos do sistema, considerando todas as formas possíveis de acesso;

c) a profundidade total foi escolhida por demonstrar a centralidade da área de estudo em relação à malha urbana.

Gerado o mapa, optou-se por se realizar primeiramente análises gerais e como essas se inter-relacionam com as percepções presenciadas e vividas nas cidades, estas que serão abordadas a seguir. Para isso as duas medidas sintáticas utilizadas foram integração global, e a profundidade, justamente por conseguir dar um panorama geral a ser analisado.

\section{RESULTADOS}

Os valores obtidos para os segmentos que representam as vias que constituem o triângulo central, apresentados na Tabela 1, indicam a importância relativa dessa área da cidade em relação aos segmentos que representam a totalidade do sistema de vias da malha urbana de juiz de fora, considerados os procedimentos para figuração dos mesmos indicados na metodologia.

Foi possível observar aspectos relativos à configuração urbana de Juiz de Fora e verificar que a cidade apresenta características espaciais diretamente ligadas ao espraiamento urbano devido ao seu desenvolvimento linear ao longo do eixo do Rio Paraibuna e sua geomorfologia, perceptíveis nas análises obtidas por meio das medidas sintáticas globais Integração (Integration
$\mathrm{HH}$ ), Profundidade Média (Mean Depth) e Profundidade Total (Total Depth).

Tabela 1: Valores das medidas sintáticas para raio " $n$ "

\begin{tabular}{|c|c|c|c|c|}
\hline Via & REF1 & $\begin{array}{c}\text { Integration } \\
\mathrm{HH}\end{array}$ & $\begin{array}{c}\text { Mean } \\
\text { Depth** }\end{array}$ & $\begin{array}{c}\text { Total } \\
\text { Depth** }\end{array}$ \\
\hline $\begin{array}{l}\text { Rua Floriano } \\
\text { Peixoto }\end{array}$ & 5 & 0.420807 & 26.569 & 276079 \\
\hline Rua Halfeld & 2 & 0.425799 & 26.2693 & 279264 \\
\hline $\begin{array}{l}\text { Rua Marechal } \\
\text { Deodoro }\end{array}$ & 13 & 0.421763 & 26.5111 & 275477 \\
\hline $\begin{array}{l}\text { Rua Espírito } \\
\text { Santo }\end{array}$ & 28 & 0.420805 & 26.5691 & 276080 \\
\hline $\begin{array}{l}\text { Rua Oscar } \\
\text { Vidal }\end{array}$ & 29 & 0.420812 & 26.5688 & 276076 \\
\hline $\begin{array}{l}\text { Rua Santo } \\
\text { Antônio }\end{array}$ & 38 & 0.414008 & 26.9889 & 280442 \\
\hline $\begin{array}{l}\text { Rua Braz } \\
\text { Bernardino }\end{array}$ & 8114 & 0.420375 & 26.5953 & 276532 \\
\hline $\begin{array}{l}\text { Rua Barbosa } \\
\text { Lima }\end{array}$ & 8116 & 0.407549 & 27.4008 & 284722 \\
\hline $\begin{array}{l}\text { Rua Santa } \\
\text { Rita }\end{array}$ & 8117 & 0.420497 & 26.5879 & 276275 \\
\hline Rua São João & 8118 & 0.420519 & 26.5866 & 276261 \\
\hline Rua Mister & 8119 & 0.406839 & 27.4469 & 285201 \\
\hline Moore & 8120 & 0.42035 & 26.5669 & 276338 \\
\hline $\begin{array}{l}\text { Avenida } \\
\text { Getúlio Vargas } \\
\text { Avenida }\end{array}$ & 8122 & 0.422815 & 26.4476 & 274817 \\
\hline $\begin{array}{l}\text { Francisco } \\
\text { Bernardino }\end{array}$ & 8124 & 0.425746 & 26.2724 & 272997 \\
\hline $\begin{array}{l}\text { Rua Batista de } \\
\text { Oliveira }\end{array}$ & 8125 & 0.412073 & 27.111 & 281710 \\
\hline $\begin{array}{l}\text { Av. Barão do } \\
\text { Rio Branco }\end{array}$ & 9816 & 0.437431 & 25.5973 & 265982 \\
\hline
\end{tabular}

\section{DISCUSSÃO}

A medida integração $\mathrm{HH}$ (figuras 3 e 4) mostra a área do triângulo central de Juiz de fora como altamente integrada em relação à malha urbana como um todo, favorecendo o fluxo de pessoas e a concentração de serviços e áreas de encontro social, como de fato ocorre.

Todas as vias localizadas no triângulo central apresentam um alto valor de integração, confirmando que a malha urbana, embora espraiada e tendendo à linearidade ao longo do vale do Paraibuna, desenvolveu-se mantendo o núcleo urbano original como seu centro. Os valores de integração medidos nos segmentos localizados nessa área variam entre 0.406839 e 0.437431 , na faixa dos maiores valores encontrados na análise.

As ruas Halfeld e Marechal Deodoro, que figuram entre as mais antigas e tradicionais no comércio e no fluxo de pessoas e serviços demonstram-se altamente integradas (Com valores de Integração HH de 0.425799 e 0.421763 , respectivamente), figurando entre as vias transversais à Avenida Barão do Rio Branco com os maiores valores dentro do sistema para esta medida.

Estes valores de integração estendem-se por todo o segmento das vias citadas, embora note-se que, na realidade, a "parte alta" (denominação derivada da divisão virtual do segmento entre a rua Santo Antônio e Avenida Olegário Maciel) de ambas tenham um caráter menos comercial e mais direcionado à ocupação residencial devido à altimetria que pode ser observada na Figura 02. 


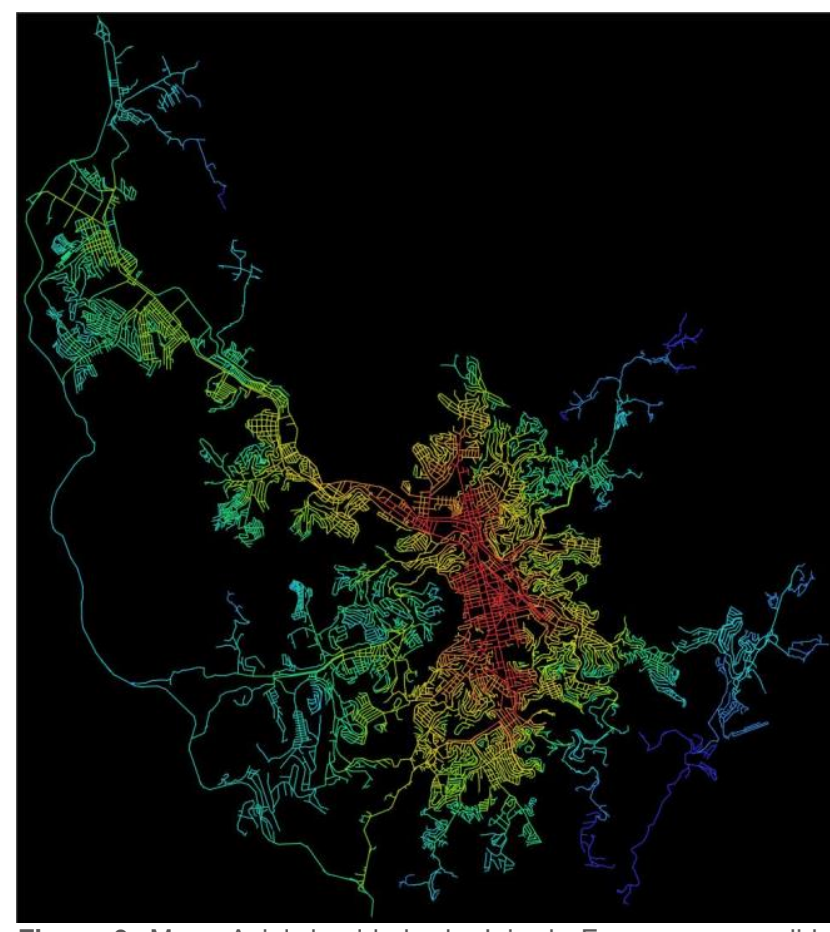

Figura 3: Mapa Axial da cidade de Juiz de Fora para a medida sintática Integração HH. Fonte: autores.

A ampliação permite perceber ainda que as diversas galerias (representadas pelas pequenas linhas verticais que cruzam as vias analisadas) cumprem importante papel na integração, aumentando a permeabilidade dos grandes quarteirões centrais entre a Avenida Barão do Rio Branco $(A)$ e rua Batista de Oliveira $(K)$, principalmente.

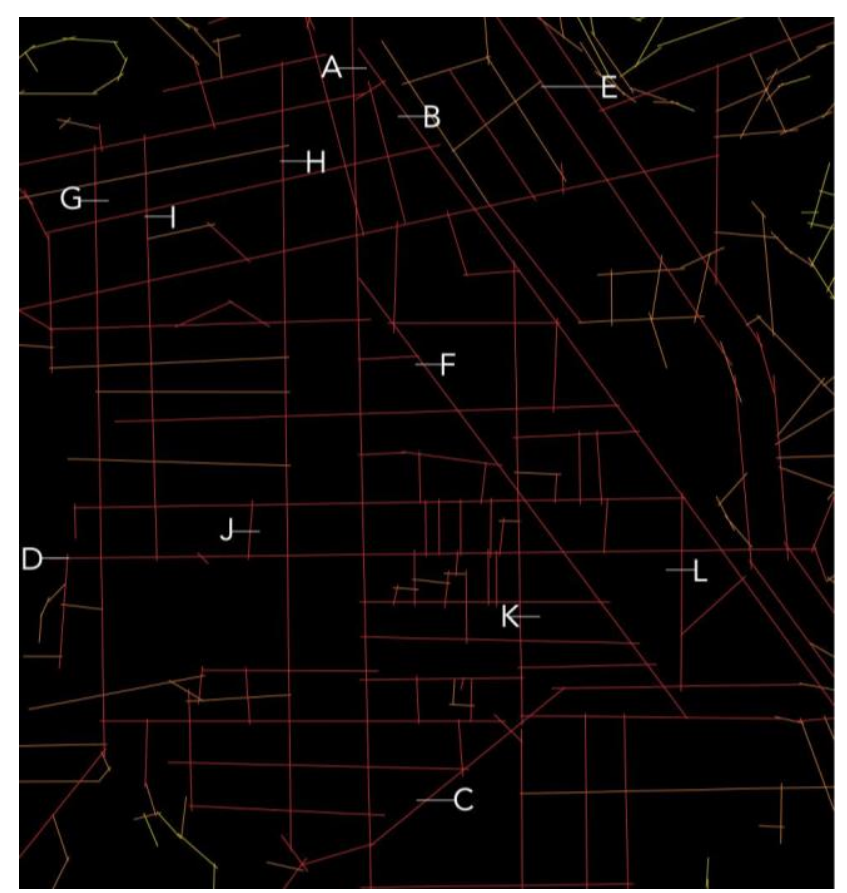

Figura 4: Ampliação do Mapa Axial da cidade de Juiz de Fora para a medida sintática Integration $\mathrm{HH}$, mostrado o triângulo central. Fonte: autores.

A medida sintática Mean Depth (profundidade média) apresenta menor valor na área do triângulo central, aumentando gradativamente à medida em que nos afastamos da interseção dos segmentos que representam a rua Halfeld e a Avenida Barão do Rio Branco.

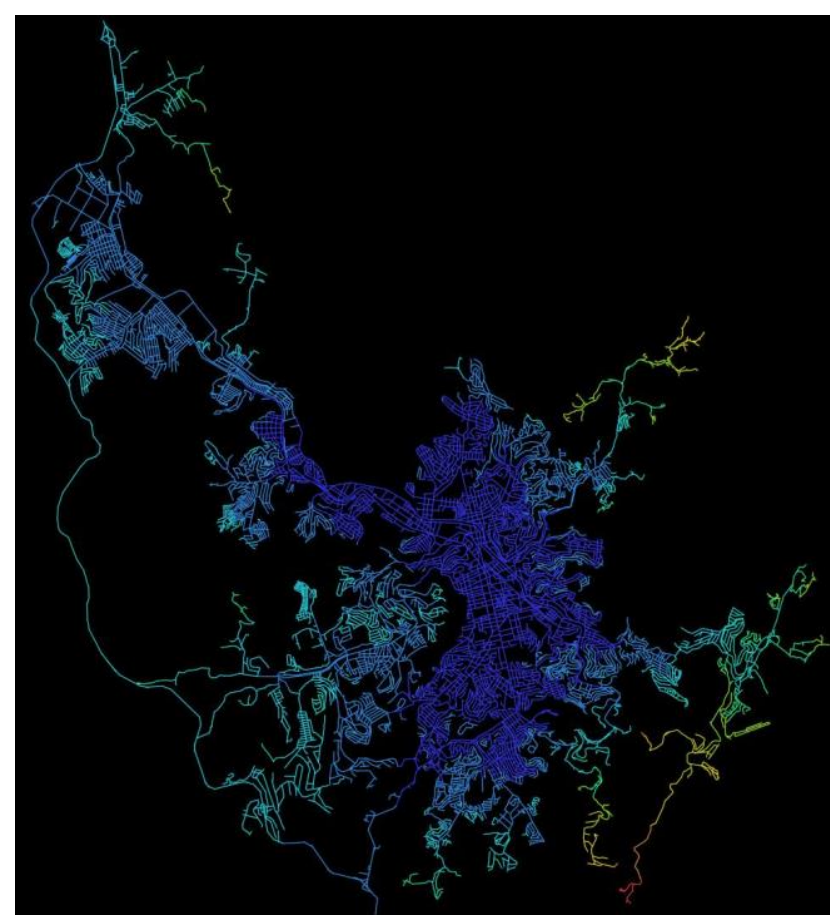

Figura 5: Mapa Axial da cidade de Juiz de Fora para a medida sintática Mean Depth. Fonte: autores.

Pode-se observar que, no centro da imagem, tem-se a mudança brusca da gradação de azul escuro para azul claro logo após um vazio. Essa diferença de gradação pode ser explicada pela presença do morro do imperador (ou morro do cristo, cuja topografia impede o acesso direto a partir do centro, já que essa medida representa o caminho topológico médio mais curto entre os segmentos.

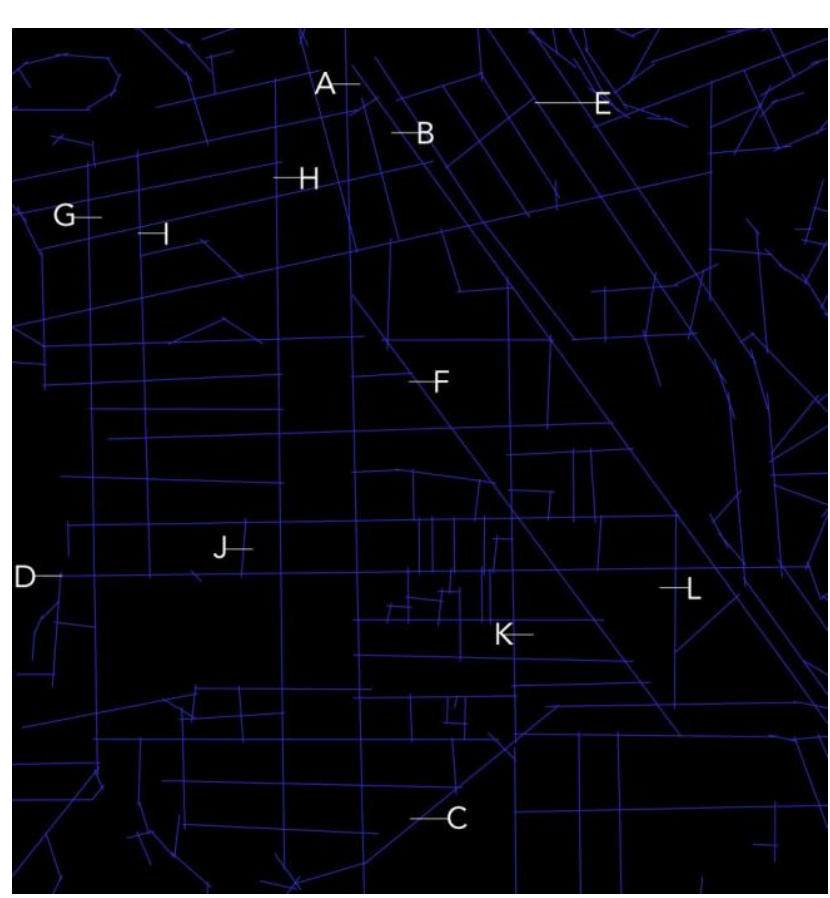

Figura 6: Ampliação do Mapa Axial da cidade de Juiz de Fora para a medida sintática Mean Depth, mostrado o triângulo central. Fonte: autores.

A medida sintática Total Depth (profundidade total) traz a rua Halfeld como uma das de menor profundidade no sistema, atrás apenas de 3 avenidas que se confirmam como eixos estruturadores, sendo elas a) Av. Barão do 
Rio Branco, que conecta a cidade no sentido norte-sul; b) Avenida Brasil, que conecta a cidade no sentido noroestesudeste; e c) Avenida dos Andradas, principal ligação entre a avenida Barão do Rio Branco e a região oeste da cidade.

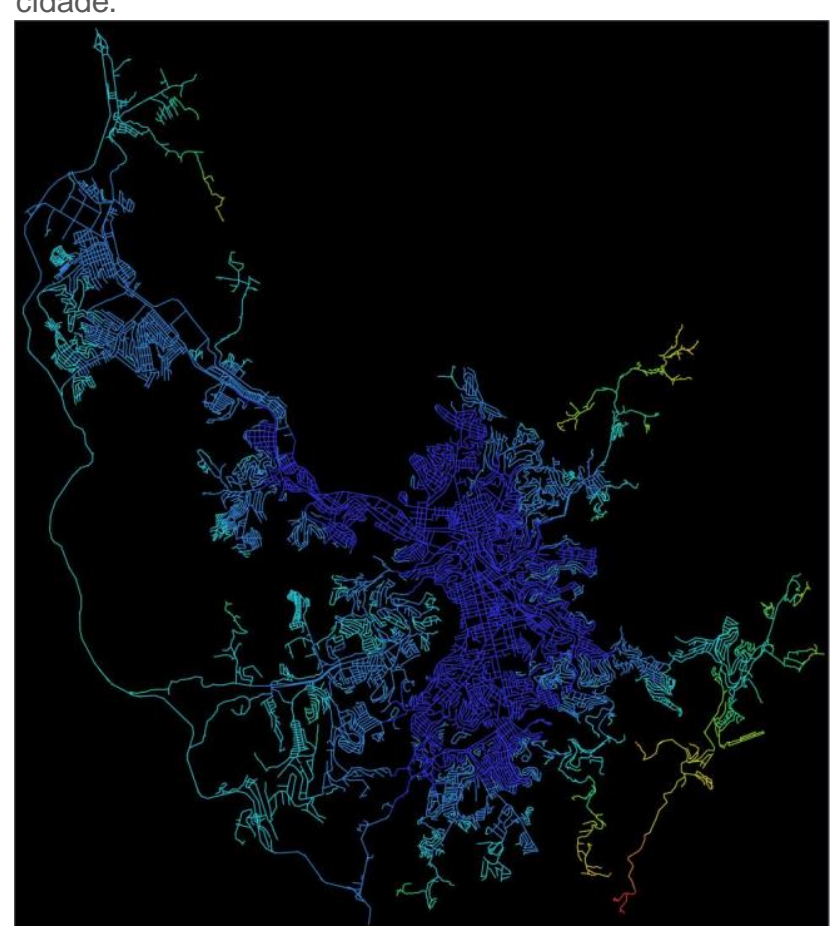

Figura 7: Mapa Axial da cidade de Juiz de Fora para a medida sintática Total Depth. Fonte: autores.

Embora profundidade total considere que a parte da cidade alta (segmentos azul-claros à esquerda do triângulo central, após o vazio urbano) possuam valores de profundidade intermediários, já que essa medida analisa a distância linear entre o centro dos segmentos, na realidade 0 acesso entre as áreas é dificultado pela altimetria, que chega a variar cerca de $200 \mathrm{~m}$ entre as áreas.

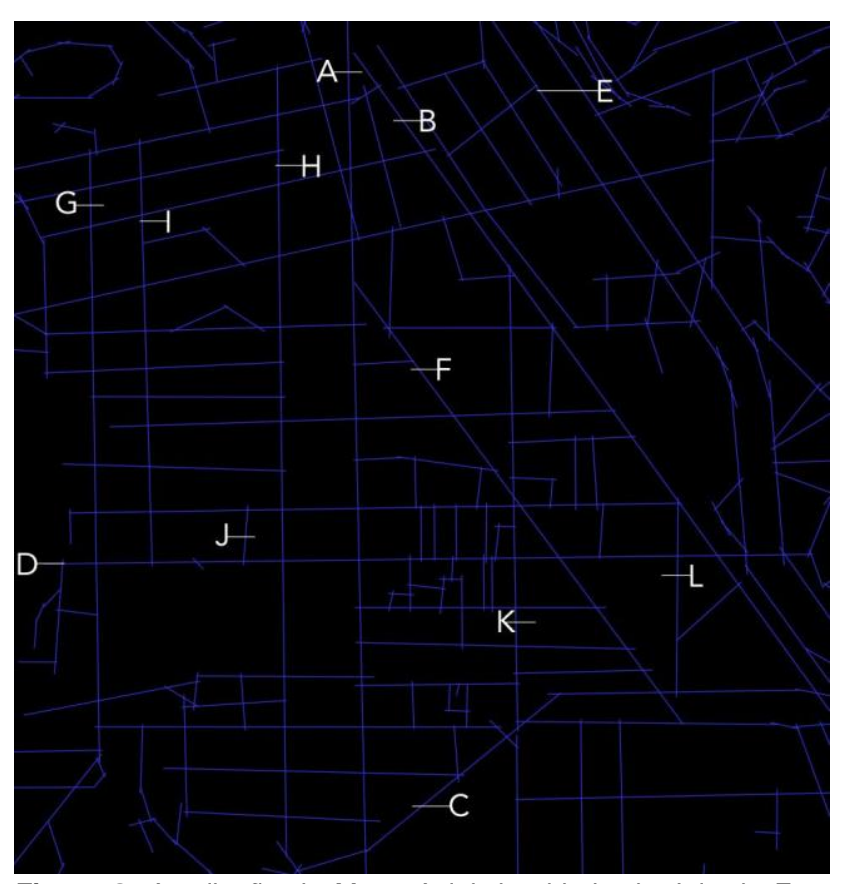

Figura 8: Ampliação do Mapa Axial da cidade de Juiz de Fora para a medida sintática Total Depth, mostrado o triângulo central.
O valor de profundidade total para a rua Halfeld (279264), representada pela letra $D$ na figura 8 , como um dos menores valores para essa medida no sistema, contrasta diretamente com o maior valor encontrado para um segmento (aproximadamente $1,43 \mathrm{E}+10$ ), representado na parte inferior direita da figura 7 pelos segmentos de cor vermelha.

Como essa medida sintática representa a distância linear entre o centro de um segmento e o centro de todos os demais segmentos do sistema, é possível perceber que o triângulo central de Juiz de Fora apresenta-se também como a área com distância relativa mais equilibrada em relação à malha urbana.

O gráfico de dispersão para as medidas sintáticas Profundidade Total no eixo x e Integração HH no eixo y (figura 9) demonstra que os valores obtidos são consistentes devido à proximidade dos pontos que representam os segmentos, sem a existência de grandes desvios.

É possível perceber que, à medida em que a integração diminui, a profundidade total aumenta, definindo essas medidas como inversamente proporcionais. Esse resultado é, ainda, coerente com a ideia de que, quanto mais distantes os segmentos, menos integrados eles estão.

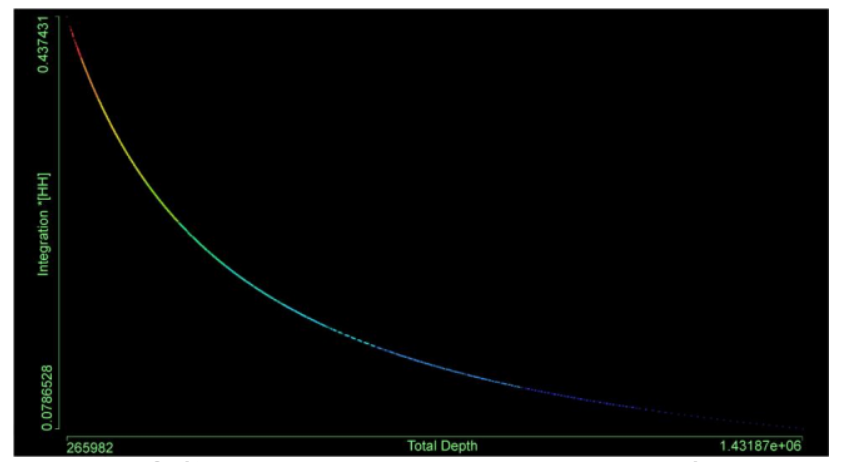

Figura 9: Gráfico de dispersão para as medidas sintáticas Total Depth no eixo x e Integration HH no eixo y. Fonte: autores.

O gráfico de dispersão para as medidas Profundidade Total no eixo $x$ e profundidade média no eixo y (figura 10) demonstra que, embora as definições das medidas sejam diferentes, os resultados são diretamente proporcionais e os valores aumentam à medida em que a posição dos segmentos na malha urbana vai se distanciando da área do triângulo central.

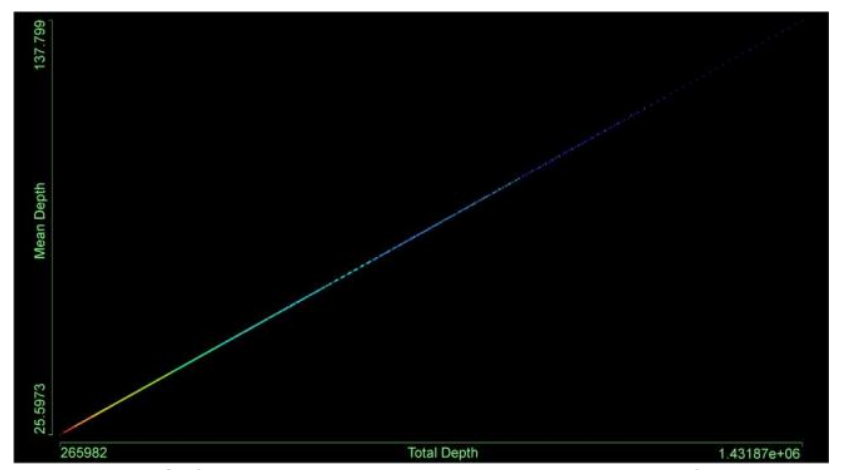

Figura 10: Gráfico de dispersão para as medidas sintáticas Total Depth no eixo x e Mean Depth no eixo y. Fonte: autores. 


\section{CONCLUSÃO}

Os dados obtidos e as análises realizadas confirmam algumas percepções correntes dos autores sobre a cidade de Juiz de Fora no que tange às relações entre seus eixos estruturantes e integração entre as áreas urbanas, principalmente na importância da área central para a atração de fluxos e a realização de atividades sociais.

Ao analisarmos a relação configuracional dos eixos com maior potencial de integração, percebe-se que a Avenida Barão do Rio Branco, uma das primeiras vias do núcleo urbano original, desempenha papel imprescindível nas conexões urbanas, embora localizada no eixo norte-sul da cidade, enquanto o maior eixo desenvolve-se nos sentido noroeste-sudeste.

A confluência entre a rua Halfeld e a Avenida Barão do Rio Branco há muito é considerada o ponto nevrálgico da malha urbana, tanto pelos habitantes da cidade quanto por estudos anteriores (Lessa, 1985; Miranda, 1990; Abdalla, 1996; Braida, 2008; Sampaio, 2015), o que é corroborado pela análise do potencial desses eixos pela Teoria da Lógica Social do Espaço.

A visão de que, nos sistemas urbanos, a configuração seria o fator primário na movimentação e que, em geral, a presença de atratores decorre da configuração é questionável, uma vez que o potencial de atração de uma rua pode não encontrar reconhecimento. Netto (2013) aponta corretamente que a definição de novos caminhos intraurbano pode ser influenciada por atratores posicionados na rede ou nas bordas urbanas, como decisões e processos dependentes e ativos simultaneamente. Essa questão pode ser verificada nos valores de integração e profundidade das ruas Halfeld e Marechal Deodoro.

Embora as análises retornem valores homogêneos para toda a extensão de um determinado segmento, como citado nos casos da divisão entre parte alta e baixa das ruas Halfeld e Marechal Deodoro, a geomorfologia e mesmo o histórico de ocupação e as diversas formas de apropriação do espaço urbano não são efetivamente representados nos resultados. Dessa forma, esses elementos devem ser integrados aos dados obtidos através do mapa axial para que se tenha um resultado mais adequado à realidade, ponderando o uso potencial e a realidade dos segmentos em análise.

Por fim, algumas percepções anteriores, como a importância da avenida Barão do Rio Branco na estruturação da malha urbana e a proeminência da rua Halfeld como a mais importante do centro da cidade são corroboradas, enquanto novos aspectos como a importância da Avenida dos Andradas como eixo estruturador de acesso entre o centro e a região oeste, bem como a necessidade de realização das análises sintáticas em conjunto com a influência da topografia são delineadas, podendo constituir-se em desdobramentos futuros da pesquisa.

\section{AGRADECIMENTOS}

Agradecemos à Universidade Federal de Juiz de Fora e à CAPES pelo suporte concedido.

\section{REFERÊNCIAS}

Abdalla, J. G. F. (1996). Multivalência da arquitetura das galerias de Juiz de Fora: fascínio e identidade entre o público e o privado. Juiz de Fora: [s.e.]. (Relatório de pesquisa, não publicado).

Gehl, J. \& Svarre, B. (2018) A vida na cidade: como estudar. São Paulo, BR: Perspectiva.

Hillier, B. (1996). Space Is The Machine: A Configurational Theory Of Architecture. Cambridge, EN: Cambridge Press.

Hillier, B. \& Hanson, J. (1984) The social logic of space. Cambridge, EN: Cambridge Press.

Hillier, B. Penn, A.; Hanson, J.; Grajewskil, T. Xu, J. (1993). Natural movement: or, configuration and attraction in urban pedestrian movement. Environment and Planning B, Londres, vol 20(1), 29-66

Holanda, F.; Ribeiro, R.; Medeiros, V. (2008). Brasilia, Brazil: economic and social costs of dispersion. In: ISOCARP Congress, 44, 2008, Dalian. Proceedings... Dalian: ISCRP/UPSC.

Lessa, J. (1985) Juiz de Fora e seus pioneiros - do caminho novo à proclamação. Juiz de Fora, BR: EdUFJF.

Medeiros, V. (2006) Urbis brasiliae ou sobre cidades do Brasil.Tese (Doutorado em Urbanismo) - Faculdade de Arquitetura e Urbanismo, Universidade de Brasília, Brasília.

Miranda, S. R. (1990). Cidade, capital e poder: políticas públicas e questão urbana na velha Manchester Mineira. Dissertação de Mestrado. Universidade Federal Fluminense.

Netto, Vinícius O. 2013. "O que a Sintaxe Espacial não é?" Arquitextos, no161, ano 14 (october): 1809-6298. Retrieved from http://www.vitruvius.com.br/revistas/read/arquitextos/14.161/4916

Paula, F. B. R. de (2008). Passagens em rede: a dinâmica das galerias comerciais e dos calçadões nos centros de Juiz de Fora e de Buenos Aires. Dissertação (Mestrado em urbanismo) Programa de Pós-Graduação em Urbanismo, Universidade Federal do Rio de Janeiro.

Pereira, R. H. M., Holanda, F. R. B. de, Medeiros, V. A. S. de, \& Barros, A. P. B. G. (2011). The use of space syntax in urban transport analysis: limits and potentials. Discussion. Brasília: Institute for Applied Economic Research - IPEA.

Sampaio, J. C. R. (2015). Triângulo da memória de Juiz de Fora. [s.I.]: IPHAN. Retrieved from http://portal.iphan.gov.br/uploads/ publicacao/Artigo_do_Patrimonio_TrigMemoJF_Julio_Sampaio.pd f. 